\title{
Structural Characterization and Dielectric Studies of Superparamagnetic Iron Oxide Nanoparticles
}

\author{
D. Sivakumar*,****, K. Chandra Babu Naidu**, K. Prem Nazeer****, M. Mohamed Rafi****, \\ G. Ramesh kumar $* * * *$, B. Sathyaseelan $* * * *$, G. Killivalavan****, and A. Ayisha Begam $* * * * *$ \\ *Department of Physics, Sree Krishna College of Engineering, Unai, Anaicut -632 101, Tamilnadu, India \\ **Department of Humanities and Sciences, Srinivasa Ramanujan Institute of Technology, Anantapuramu-515 701, A.P, India \\ ${ }^{* * *} P G$ \& Research Department of Physics, Islamiah college, Vaniyambadi -635 752, Tamilnadu, India \\ ****Department of Physics, University College of Engineering-Arni, 632 326, Tamilnadu, India \\ $* * * * *$ Department of Physics, Avinashilingam Institute for Home Science and Higher Education, \\ Coimbatore -641 043, Tamilnadu, India
}

(Received December 3, 2017; Revised March 13, 2018; Accepted March 19, 2018)

\begin{abstract}
Superparamagnetic iron oxide nanoparticles (SPIONs) have been prepared without using surfactants to assess their stability at different time intervals. The synthesized particles were characterized by X-ray diffraction, Fourier-transform infrared spectroscopy, ultraviolet-visible-near infrared spectroscopy, and energy dispersive spectroscopy. Field emission scanning electron microscopy and high-resolution transmission electron microscopy images of the samples were also investigated. The average particle size was measured to be $12.7 \mathrm{~nm}$ even in the polydispersed form. The magnetic and dielectric characteristics of the $\mathrm{Fe}_{3} \mathrm{O}_{4}$ nanoparticles have also been studied and discussed in detail.
\end{abstract}

Key words : Dielectric properties, Impedance, Magnetic properties

\section{Introduction}

$\mathbf{I}_{\mathrm{t} t}^{\mathrm{n}}$ $\mathrm{n}$ the past decades, attention has been increasingly paid to the design and assembly of magnetic nanomaterials with controlled shapes and morphologies. Magnetic nanoparticles present opportunities in technological applications such as protein and enzyme immobilization, bio-separation, immunoassays, hyperthermia, drug delivery, and magnetic resonance imaging (MRI). They exhibit interesting properties owing to the presence of iron cations in two valence states, namely $\mathrm{Fe}^{2+}$ and $\mathrm{Fe}^{3+}$, in the inverse spinel cubic structure. $^{1,2)}$

Magnetite $\left(\mathrm{Fe}_{3} \mathrm{O}_{4}\right)$ nanoparticles can be synthesized by several routes, including co-precipitation, sol-gel method, colloidal route, solvothermal synthesis, hydrothermal method, micro-emulsion method, and thermal decomposition. ${ }^{3)}$ J.B. Mamani et al. ${ }^{4)}$ prepared magnetic fluids of $\mathrm{Fe}_{3} \mathrm{O}_{4}$ using chemical synthesis and revealed that both in vitro and in vivo studies have yielded homogeneous magnetic nanoparticles with an average diameter of $12.6 \mathrm{~nm}$. Furthermore, their magnetization measurements confirmed the existence of the superparamagnetic behavior of $\mathrm{Fe}_{3} \mathrm{O}_{4}$ nanoparticles above the blocking temperature $\left(\mathrm{T}_{\mathrm{B}}=80 \mathrm{~K}\right)$, where there is no coercivity. This property could be effectively exploited for the monitoring and tracking of magnetic nanoparticles in MRI and for magnetohyperthermia techniques.

Iron oxide nanoparticles synthesized by the mechanical ultrasonication method exhibited particle sizes of $6 \mathrm{~nm}$ with spherical morphology. ${ }^{5)}$ Their magnetic saturation and coercivity at room temperature (RT) were found to be 3.7 $\mathrm{emu} / \mathrm{g}$ and $114 \mathrm{Oe}$, respectively. In addition, there are a variety of reports on the synthesis of $\mathrm{Fe}_{3} \mathrm{O}_{4}$ nanoparticles. ${ }^{6-23)}$

Sara Gil et $a l .{ }^{24)}$ demonstrated that $\mathrm{Fe}_{3} \mathrm{O}_{4}$ nanoparticles could be coated with di-carboxylic terminated polyethylene glycol to construct MRI dual modality molecular probes for vivo colorectal and gastric carcinoma detections. M. Morel et $a l .{ }^{25)}$ showed that oleic acid-coated magnetite nanoparticles generally agglomerate. Furthermore, the agglomeration observed in the HRTEM images was attributed to the Van der Waals force between the particles.

The main objective of the present work is to synthesize superparamagnetic iron oxide nanoparticles without using surfactants. Most of the reports emphasize the use of capping agents during synthesis to improve stability. To the best of our knowledge, only few reports on SPIONs synthesis using the co-precipitation technique without any encapsulating agent exist. Although the properties of iron oxide nanoparticles have been studied well, the stability of their magnetic and dielectric properties have not been investigated.

\footnotetext{
Corresponding author: K. Prem Nazeer

E-mail : nazeerprem13@gmail.com

Tel : +919894600924
} 


\section{Experimental Procedure}

\subsection{Materials used}

The starting materials ferric chloride hexahydrate $\left(\mathrm{FeCl}_{3} \cdot 6 \mathrm{H}_{2} \mathrm{O}\right)$, ferrous sulfate heptahydrate $\left(\mathrm{FeSO}_{4} \cdot 7 \mathrm{H}_{2} \mathrm{O}\right)$, ammonia $\left(\mathrm{NH}_{3}\right)$, and ethanol $\left(\mathrm{C}_{2} \mathrm{H}_{6} \mathrm{O}\right)$ were obtained from Fisher scientific, India. The purity of the reactant chemicals was $\geq 99.9 \%$.

\subsection{Synthesis of SPIONs}

To synthesize SPIONs, $1.49 \mathrm{~g}$ of $\mathrm{FeCl}_{3} \cdot 6 \mathrm{H}_{2} \mathrm{O}$ and $0.765 \mathrm{~g}$ of $\mathrm{FeSO}_{4} \cdot 7 \mathrm{H}_{2} \mathrm{O}$ were mixed and heated at $60^{\circ} \mathrm{C}$ under a nitrogen atmosphere. An $8 \mathrm{M}$ ammonia solution was then added drop wise to the parent solution until the $\mathrm{pH}$ became 10. The resultant solution was maintained at $60^{\circ} \mathrm{C}$ for $2 \mathrm{~h}$, and centrifuged at 10,000 rpm for $10 \mathrm{~min}$. The sediment particles were thoroughly washed with distilled water three times to remove the byproducts. Thereafter, the particles were washed several times with ethanol. The product was finally dried in an oven at $100^{\circ} \mathrm{C}$ for $3 \mathrm{~h}$.

\subsection{Characterization of SPIONs}

The crystal structure of the SPIONs was ascertained by $\mathrm{x}$-ray powder diffraction (XRD) using a Bruker D8 advance diffractometer with $\mathrm{Cu}-\mathrm{K} \alpha$ radiation (1.5406 $\AA$ ) operating at $40 \mathrm{kV}$ and $30 \mathrm{~mA}$. The FTIR spectrum of the SPION particles was recorded using a BRUKER 10049391IR spectrometer at RT in the frequency range $500-4000 \mathrm{~cm}^{-1}$. The UV-Vis-NIR absorption spectrum was measured between 200 and $2500 \mathrm{~nm}$ using a Varian Cary 5000 spectrophotometer. The morphology of the SPIONs was analyzed by FESEM using a JEOL-JSM-6390 LV, while its particle size was determined by HRTEM using a JEOL JEM 2100. Moreover, the magnetic properties of the SPIONs were studied by vibrating sample magnetometry (VSM) using a Lakeshore 7410 at RT. The dielectric parameters of the sample, such as dielectric constant $\left(\varepsilon_{\mathrm{r}}\right)$, dielectric loss $(\tan \delta)$, and $\mathrm{AC}$ conductivity, were studied using HIOKI 3532-50 LCR HiTESTER at various temperatures (350 K$400 \mathrm{~K}$ ) in the frequency range $100 \mathrm{~Hz}-5 \mathrm{MHz}$.

\section{Results and Discussion}

\subsection{X-ray diffraction (XRD)}

The XRD pattern of the as-synthesized SPIONs is shown in Fig. 1. All the diffraction peaks were indexed to the cubic inverse spinel structure of $\mathrm{Fe}_{3} \mathrm{O}_{4}$, similar to that of the bulk $\mathrm{Fe}_{3} \mathrm{O}_{4}{ }^{26)}$ with a lattice constant $\mathrm{a}=\mathrm{b}=\mathrm{c}=8.381 \AA$ and space group Fd3m. The observed peaks could be assigned to the (hkl) reflections from the (220), (311), (400), (422), (511), (440), (620), and (622) planes in the order of ascending $2 \theta$ values. No impurities were observed across the entire range of the profile. The interplanar distance (d-spacing) of the cubic lattice was estimated by Bragg's diffraction equation: $2 d \sin \theta=n \lambda$ for $n=1$. The lattice parameter of the cubic unit cell (a) was estimated by the equation (1):

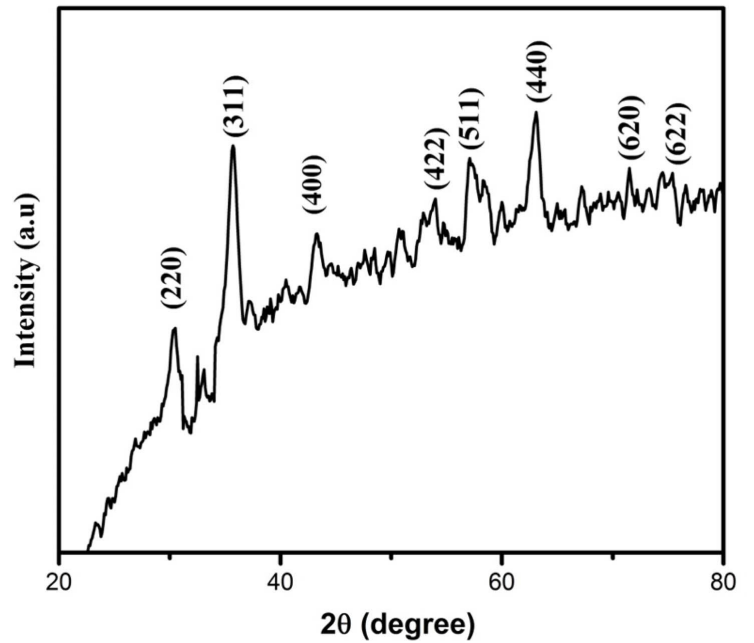

Fig. 1. X-ray diffraction pattern of SPIONs.

$$
d=\frac{a}{\sqrt{h^{2}+k^{2}+l^{2}}}
$$

where $d$ is the $\mathrm{d}$-spacing and $\mathrm{h}, \mathrm{k}$, and $\mathrm{l}$ are the Miller indices (h k l). The calculated d-spacing and lattice parameters match the standard data reported for magnetite (JCPDS 851436). The average crystallite size was calculated from the major diffraction peak of (311) using the Debye-Scherrer formula and was found to be $7 \mathrm{~nm}$. The reduction in the particle size of the sample could be collectively attributed to the purity of the starting compounds, proper control of $\mathrm{pH}$, and the optimum temperature. Furthermore, the size reduction of $\mathrm{Fe}_{3} \mathrm{O}_{4}$ nanoparticles would greatly influence their superparamagnetic behavior and blocking temperature. The variation in particle size would also affect the monitoring and tracing of magnetic nanoparticles by MRI and magnetothermal techniques, ${ }^{27)}$ as the molecular probes sensitivity strongly depends on the surface-to-volume ratio of the nanoparticles.

\subsection{Fourier transform infrared (FT-IR) analysis}

The FTIR transmission spectrum of the SPIONs is shown

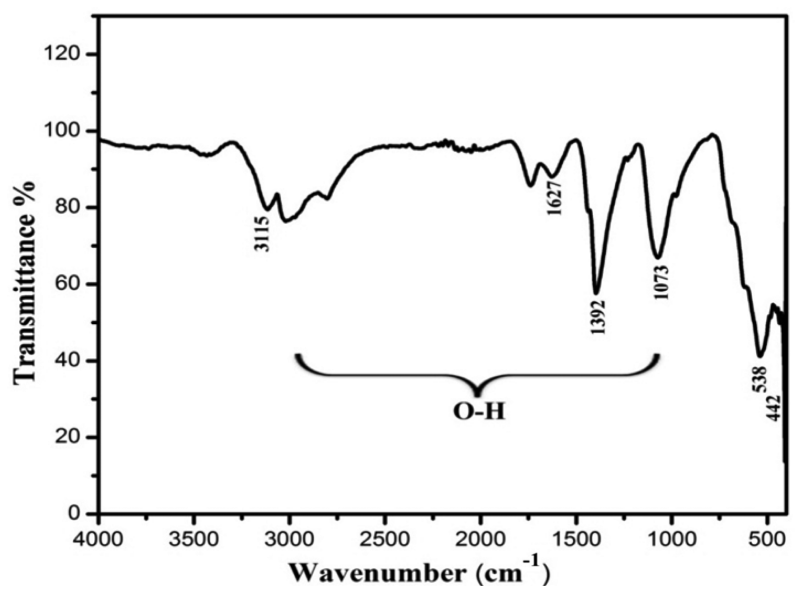

Fig. 2. Fourier transformation infrared spectrum of SPIONs. 
in Fig. 2. The two main absorption bands at 442 and 538 $\mathrm{cm}^{-1}$ correspond to the $\mathrm{Fe}-\mathrm{O}$ bonds in the tetrahedral and octahedral sites, respectively, confirming the spinel structure of pure $\mathrm{Fe}_{3} \mathrm{O}_{4}$ nanoparticles. $\left.{ }^{28-30}\right)$ This is also reflected in the planes observed in XRD, thus confirming the spinel cubic nature of the synthesized sample. The broad peaks that appear from 3500 to $3000 \mathrm{~cm}^{-1}$ and the IR absorption peaks between 1800 and $1073 \mathrm{~cm}^{-1}$ are due to the fundamental and overtonic $\mathrm{O}-\mathrm{H}$ stretching vibrations of the hydroxyl groups of water on the nanoparticles, respectively. ${ }^{31)}$ These results are consistent with the previous reports. ${ }^{32-34)}$ Despite absorbing water on their surface during synthesis, the nanoparticles exhibited sizes significantly less than those of the particles ${ }^{30)}$ obtained using microwave radiation. The particle sizes of the non-hydrated samples of $\mathrm{Fe}_{3} \mathrm{O}_{4}$ subjected to microwave irradiation ranged from 17 to $25 \mathrm{~nm}$. Here, the co-precipitation method yielded particles $7 \mathrm{~nm}$ in size even with water of crystallization.

\subsection{Optical properties of SPIONs}

The optical absorption properties of the synthesized SPIONs were measured in the wavelength region $200-1400$ nm, and are illustrated in Fig. 3. The bandgap of the nanoparticles has been calculated using the Tauc equation. (2):

$$
\alpha \mathrm{h} v=\mathrm{A}\left(\mathrm{h} v-\mathrm{E}_{\mathrm{g}}\right)^{\mathrm{n}},
$$

where $\alpha$ is the absorption coefficient, $\mathrm{A}$ is a constant, $\mathrm{h}$ is Planck's constant, $v$ is the photon frequency, $\mathrm{E}_{\mathrm{g}}$ is the bandgap energy, and the exponent $n=1 / 2$ for an allowed direct transition and 2 for an allowed indirect transition. The optical band gap of the SPIONs can be extracted from the intercept of the extrapolated linear fit of the plot of $(\alpha h v)^{2}$ versus incident photon energy ( $\mathrm{h} v)$ near the absorption edge, as shown in Fig. 3. The bandgap energy $\left(\mathrm{E}_{\mathrm{g}}\right)$ of the SPIONs was found to be $2 \mathrm{eV}$ for indirect transition, higher than the bulk $\mathrm{E}_{\mathrm{g}}$ of magnetite. Manohar et al. ${ }^{34)}$ reported that the $\mathrm{E}_{\mathrm{g}}$ of $\mathrm{Fe}_{3} \mathrm{O}_{4}$ is $0.12 \mathrm{eV}$. The deviation in refractive index was attributed to the influence of quantum confinement on the band gap of iron oxide nanoparticles. ${ }^{35)}$ Sahana et $a l .{ }^{36)}$ also demonstrated the correlation between bandgap energy and nanocrystallite size and discussed it in terms of the confinement effect. Therefore, the bandgaps of SPIONs are tunable with the proper control of particle size and morphology, which could be utilized in microwave-based device applica-

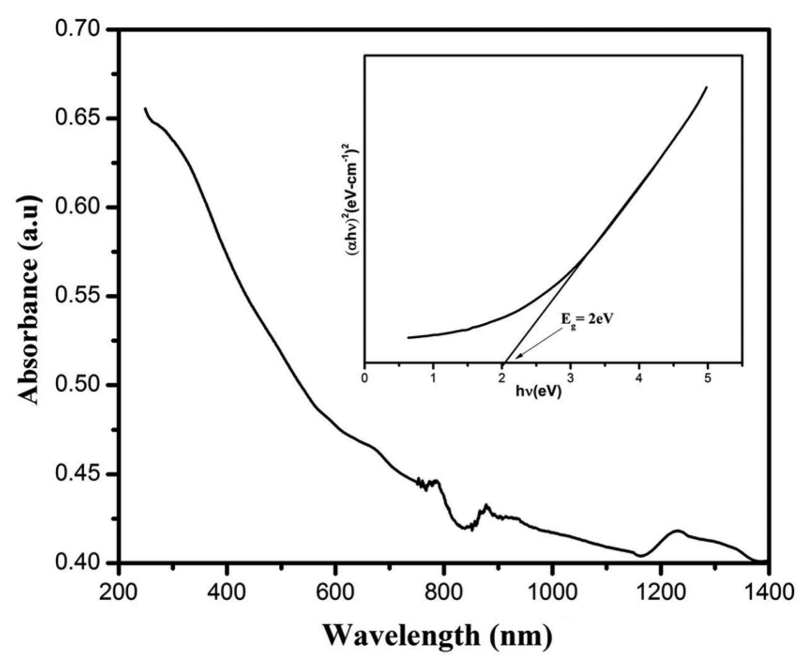

Fig. 3. UV-vis absorption spectra of SPIONs.

tions. Accordingly, the $\mathrm{E}_{\mathrm{g}}$ of the synthesized $\mathrm{Fe}_{3} \mathrm{O}_{4}$ particles has been found to be $2 \mathrm{eV}$ for the particles $12.7 \mathrm{~nm}$ in size. This considerable increase in $\mathrm{E}_{\mathrm{g}}$ for the same particle size compared with that reported by Manohar et al. ${ }^{34)}$ is quite favorable for a higher absorbance of UV radiation. Consequently, the blocking capacity of the powder in the UV regime is greater. This property will be useful for the application of the synthesized samples as sunscreen agents. Gold coating on $\mathrm{Fe}_{3} \mathrm{O}_{4}\left(\mathrm{Au}\right.$ (shell)/ $\mathrm{Fe}_{3} \mathrm{O}_{4}$ (core)) $10 \mathrm{~nm}$ in size has $50 \%$ UV blocking effects, ${ }^{23)}$ whereas the present study involving particles of size $8 \mathrm{~nm}$ revealed $65 \%$ UV absorption. Table 1 presents the shift in $\lambda_{\max }$ and $\mathrm{E}_{\mathrm{g}}$ due to the size effect.

\subsection{Field emission scanning electron microscopy} (FE-SEM) and energy dispersive $x$-ray (EDX) analysis

The FE-SEM image of the SPIONs is shown in Fig. 4(a). It was found that the nanoparticles had an almost spherical morphology with a narrow particle size distribution. The EDX spectrum, presented in Fig. 4(b), reveals the presence of stoichiometric proportions of elemental $\mathrm{Fe}$ and $\mathrm{O}$, confirming the formation of $\mathrm{Fe}_{3} \mathrm{O}_{4}$. Furthermore, the observed $\mathrm{Cl}$ and $\mathrm{S}$ peaks were attributed to the impurities from the starting compounds. These impurities could be removed after repeated washing with water and alcohol. Powders with trace amounts of $\mathrm{Cl}$ and $\mathrm{S}$ have no impact on

Table 1. Comparative Chart of Particle Sizes and $E_{g}$ Relative to the Present Work

\begin{tabular}{|c|c|c|c|c|}
\hline S.No & Literature & Synthesis methods & $\begin{array}{l}\text { Particle size obtained } \\
\text { from TEM (nm) }\end{array}$ & $\mathrm{E}_{\mathrm{g}}(\mathrm{eV})$ \\
\hline 1 & Aroonsri Priprem et al. $^{43)}$ & Co-precipitation & 15 & Not specified \\
\hline 2 & Deepak et $a l .{ }^{38)}$ & One pot thermal decomposition & 12 & Not specified \\
\hline 3 & Vineet Kumar et $a l . .^{45)}$ & Chemical co-precipitation & 19 & Not specified \\
\hline 4 & Lin Zhuang et $a l .{ }^{46)}$ & Solvothermal method & 60 & Not specified \\
\hline 5 & Manohar et $a l .^{34)}$ & Colloidal nanocrystal & 12 & 0.12 \\
\hline 6 & Present work & Co-precipitation & 12.7 & 2 \\
\hline
\end{tabular}



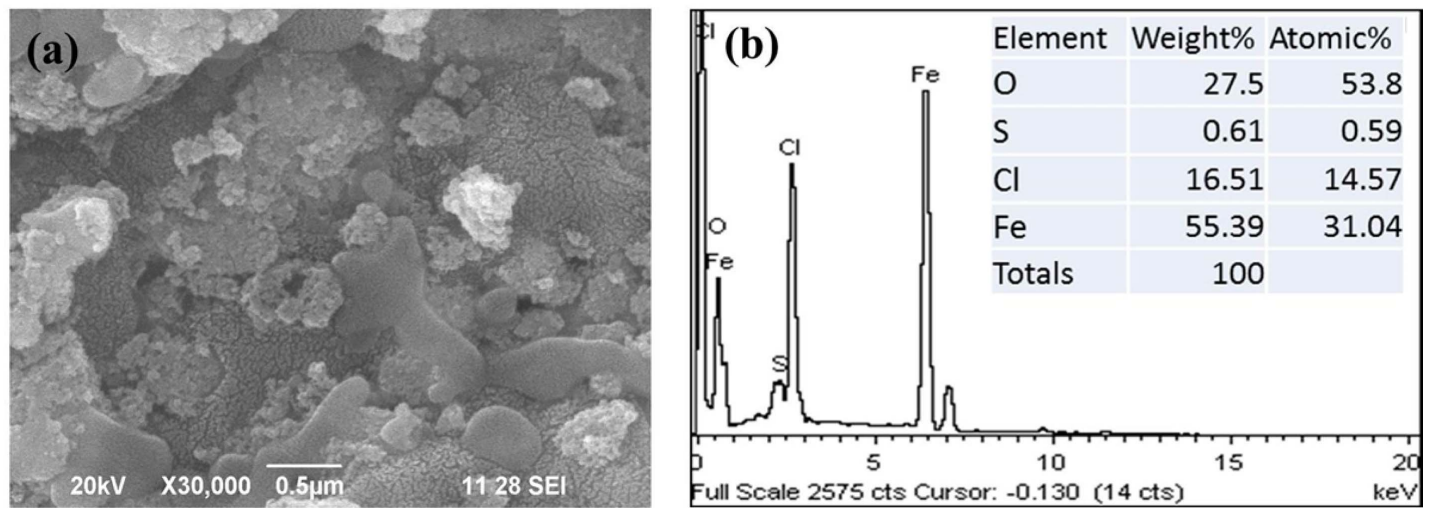

Fig. 4. (a) FE-SEM image and (b) EDX spectrum of SPIONs.

the size of the SPIONs and their morphological properties. This has been confirmed from the XRD pattern and FESEM images (not shown here) of the $\mathrm{Fe}_{3} \mathrm{O}_{4}$ powders obtained after leaching the samples with water and subsequently alcohol.

\subsection{High Resolution Transmission electron micro- scope (HRTEM) studies}

The HRTEM images of the obtained SPIONs are shown in Figs. 5(a-b). The analysis revealed that the sample consists of uniform spherical particles with an average size of $12.7 \mathrm{~nm}$ and lattice fringes. Only few particles agglomerated, because of the existence of Vander Waals interactions among them. ${ }^{37)}$ Fig. 5(c) indicates a very narrow particle size distribution of the SPIONs at $12.7 \mathrm{~nm}$. The selected area electron diffraction (SAED) pattern is shown in Fig. $5(\mathrm{~d})$, as predicted by XRD. Deepak et $a l .{ }^{38)}$ produced SPIONs with a size of around $7 \mathrm{~nm}$ and spherical morphology by the thermal decomposition process using iron (III) acetylacetonate. Compeán-Jasso et $a l .^{39)}$ prepared superparamagnetic magnetite nanoparticles with diameters of approximately $15 \mathrm{~nm}$ by a forced hydrolysis method. Maleki

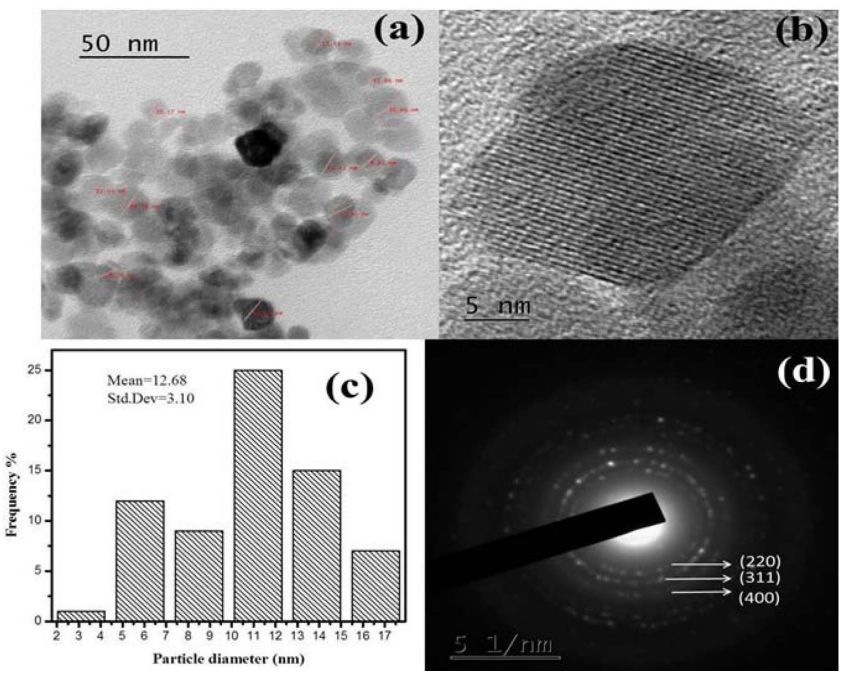

Fig. 5. (a-b) HRTEM and lattice fringes, (c) particle size distribution, and (d) SAED pattern. et $a l .{ }^{40)}$ synthesized SPIONs that are surface-coated with gold and achieved a size of $8-13 \mathrm{~nm}$ with a narrow size distribution. The particle sizes of the SPIONs obtained from other methods have also been compared with our work, as shown in Table $1 .^{41-45)}$

\subsection{Magnetic properties of SPIONs}

Magnetization measurements were conducted at RT to obtain parameters such as saturation magnetization $\left(\mathrm{M}_{\mathrm{s}}\right)$, remanence $\left(\mathrm{M}_{\mathrm{r}}\right)$, and coercivity $\left(\mathrm{H}_{\mathrm{c}}\right)$ from the analysis of the M-H magnetization curves. The VSM results of the SPIONs are presented in Fig. 6 and Table 2. It shows that the samples possess superparamagnetic properties at RT, with negligible coercivity $\left(\mathrm{H}_{\mathrm{c}}\right)$ and remanence $\left(\mathrm{M}_{\mathrm{r}}\right)$ even in the absence of an external magnetic field. The saturation magnetization $\left(\mathrm{M}_{\mathrm{s}}\right)$ of the SPIONs is about $29.75 \mathrm{emu} / \mathrm{g}$, while that of the bulk $\mathrm{Fe}_{3} \mathrm{O}_{4}$ is $92 \mathrm{emu} / \mathrm{g} .{ }^{46)}$ When the size of magnetic nanoparticles is reduced below a critical value (12.7 $\mathrm{nm}$ for SPIONs), the $\mathrm{K}_{\mathrm{B}} \mathrm{T}$ term becomes greater than the energy barrier, causing magnetic anisotropy. Consequently, thermal energy can reorient the domains, which causes the hysteresis to diminish and results in a zero coercive field,

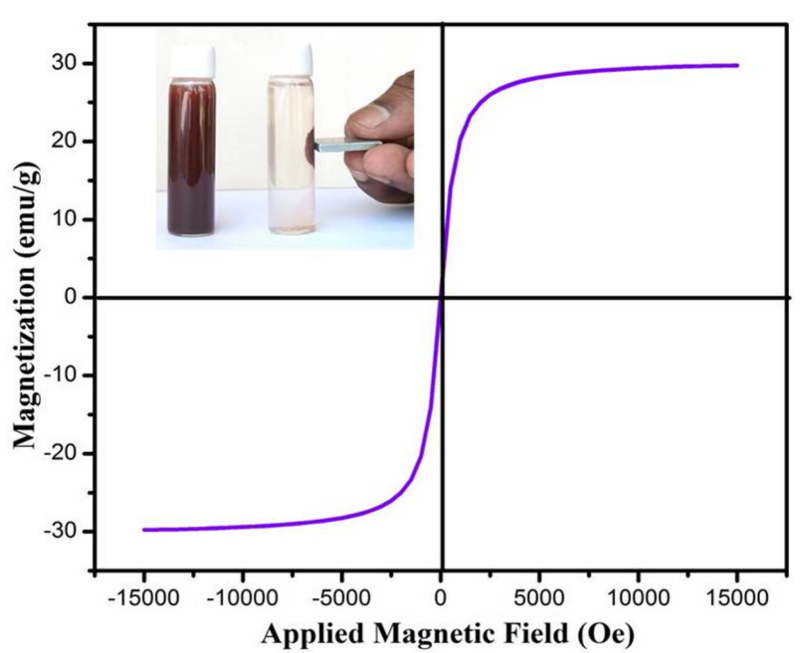

Fig. 6. VSM of the SPIONs tested by placing a magnet near the bottle. 
Table 2. Magnetic Parameters Obtained from the VSM Analysis of SPIONs

\begin{tabular}{cccccc}
\hline $\begin{array}{c}\text { Sample } \\
\text { code }\end{array}$ & $\begin{array}{c}\text { Average } \\
\text { crystallite size } \\
\text { XRD }(\mathrm{nm})\end{array}$ & $\begin{array}{c}\text { Saturation } \\
\text { Magnetization } \\
\mathrm{M}_{\mathrm{s}}(\mathrm{emu} / \mathrm{g})\end{array}$ & $\begin{array}{c}\text { Coercivity } \\
\mathrm{H}_{\mathrm{c}}(\mathrm{Oe})\end{array}$ & $\begin{array}{c}\text { Remnant } \\
\text { magnetization } \\
\mathrm{M}_{\mathrm{r}}(\mathrm{emu} / \mathrm{g})\end{array}$ & $\begin{array}{c}\text { Remanence } \\
\text { ratio } \\
\left(\mathrm{M}_{\mathrm{r}} / \mathrm{M}_{\mathrm{s}}\right)\end{array}$ \\
\hline SPIONs & 6.81 & 29.75 & 8.201 & 0.0063 & 0 \\
\hline
\end{tabular}

leading to superparamagnetism. ${ }^{47)}$ As the black particles in Fig. 6 were attracted toward the magnet, the SPIONs can easily be separated from the emulsion under an external magnetic field.

\subsection{Dielectric studies of SPIONs}

The dielectric measurements of the SPIONs were performed in the frequency range $100 \mathrm{~Hz}$ to $5 \mathrm{MHz}$ at various temperatures, 313 - $353 \mathrm{~K}$. A SPIONs sample was mounted between two electrodes. The capacitance of the parallel plate capacitor formed by the electrodes with the sample as a dielectric medium was measured.

Both the samples were sputtered with silver paste. The variation in capacitance was recorded in the frequency range $100 \mathrm{~Hz}$ to $5 \mathrm{MHz}$ at different temperatures. The plot of the dielectric constant $\left(\varepsilon_{\mathrm{r}}\right)$ versus temperature is shown in Fig. 7(a). The $\varepsilon_{\mathrm{r}}$ decreases with increasing applied frequency of SPION pellets, with a value of about 16.3 at 5 MHz. Both dielectric constant and dielectric loss $\left(\varepsilon^{\prime \prime}\right)$ were measured using the following equation ( $3 \& 4)$ :

$$
\begin{aligned}
& \varepsilon^{\prime}=\mathrm{cd} / \varepsilon_{0} \mathrm{~A}, \\
& \tan \delta=\varepsilon^{\prime \prime} / \varepsilon^{\prime},
\end{aligned}
$$

where 'c' is the capacitance, ' $d$ ' is the thickness of the sample, ' $A$ ' is the cross-sectional area, and $\varepsilon_{0}$ is the free space permittivity $\left(8.854 \times 10^{-12} \mathrm{~F} / \mathrm{m}\right)$. In Table 3 , the dispersion of $\varepsilon_{\mathrm{r}}$ with applied frequency at various temperatures is shown in Fig. 7(a). The high value of $\varepsilon_{\mathrm{r}}$ at low frequency may be ascribed to the presence of electronic, ionic, orientation, and space charge polarizations. ${ }^{48)}$ The low values at higher frequencies may be ascribed to the gradual decrease of these polarizations.

Across all the temperatures, the value of $\varepsilon_{\mathrm{r}}$ gradually decreases when the samples are probed beyond the $42 \mathrm{~Hz}$ $5 \mathrm{MHz}$ range. This may be due to the fact that the influence of the temperature-dependent space charge polarization on $\varepsilon_{\mathrm{r}}$ is only significant at frequencies below $1000 \mathrm{~Hz}$. Therefore, above this range, the $\varepsilon_{\mathrm{r}}$ values of the SPIONs are almost constant. The typical values of $\varepsilon_{\mathrm{r}}$ at $5 \mathrm{MHz}$ for various temperatures are listed in Table 3.

Similarly, the dielectric loss $\left(\varepsilon^{\prime \prime}\right)$ of the SPIONs as a function of frequency at different temperatures is shown in Fig.
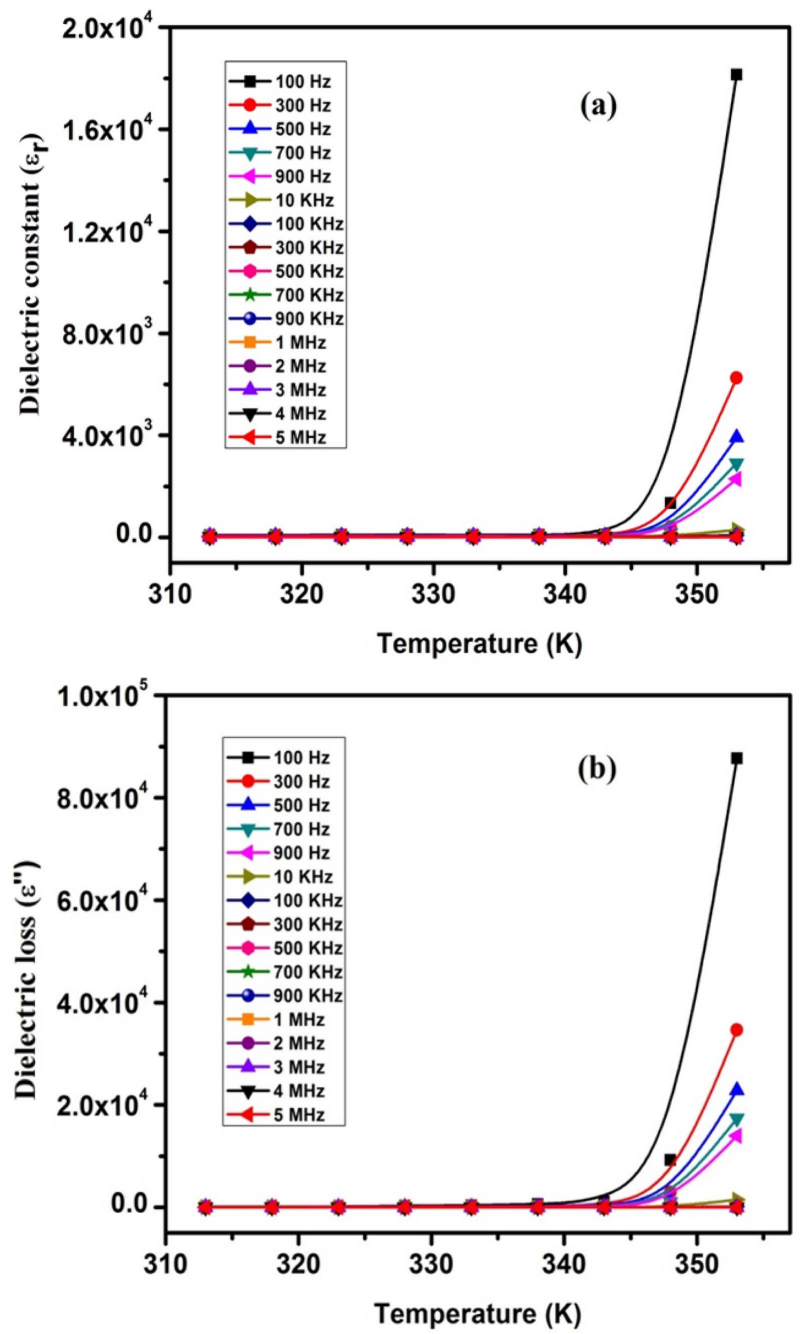

Fig. 7. Temperature dependence of (a) dielectric constant $\left(\varepsilon_{\mathrm{r}}\right)$ and $(b)$ dielectric loss $(\varepsilon ")$.

7(b). Observably, $\varepsilon^{\prime \prime}$ decreases as the frequency increases and is almost constant at higher frequencies. The trend observed could be ascribed to dipole polarization. The typical values of $\varepsilon^{\prime \prime}$ for $5 \mathrm{MHz}$ at $313 \mathrm{~K}$ is found to be 1.05 . Furthermore, the increase in dielectric loss with temperature may be attributed to increasing lattice vibrations and generation of phonons which interact with the charge carriers

Table 3. Data on the Dielectric Properties of SPIONs

\begin{tabular}{ccccccc}
\hline \multirow{2}{*}{ Sample } & $\varepsilon_{r}$ & \multirow{2}{*}{$\varepsilon^{\prime \prime}$} & \multicolumn{2}{c}{ Activation energy in (eV) } \\
\cline { 4 - 7 } & $(100 \mathrm{~Hz}-5 \mathrm{MHz})$ & $(100 \mathrm{~Hz}-5 \mathrm{MHz})$ & $\tan / \varepsilon_{\mathrm{r}}$ & $\sigma_{\mathrm{ac}}(\mathrm{S} / \mathrm{cm})$ & $\mathrm{E}_{1}$ & $\mathrm{E}_{2}$ \\
\hline SPIONs & $90.3-16.3$ & $105.73-1.05$ & 0.057 & $1.08 \mathrm{E}-03$ & $0.325-0.523$ & $0.482-0.775$ \\
\hline
\end{tabular}



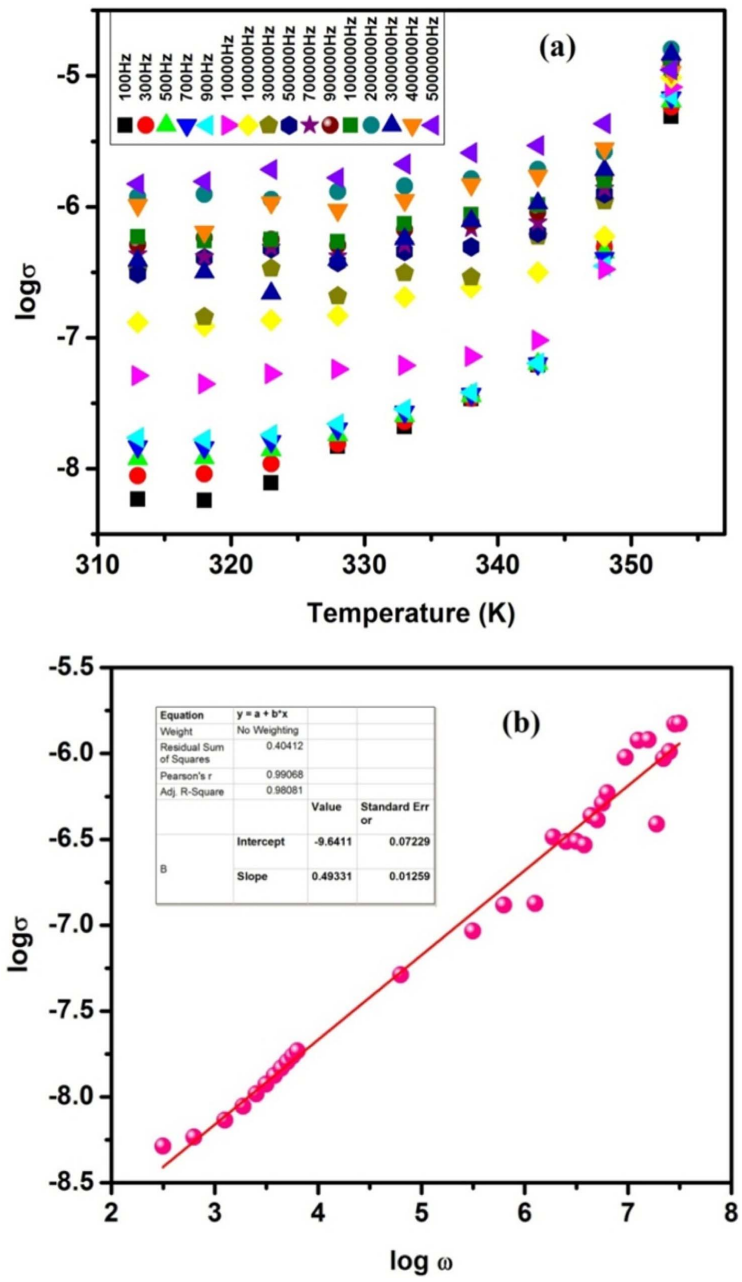

Fig. 8. (a) $\log \sigma$ versus Temperature and (b) frequency plots of SPIONs.

leading to electron phonon scattering. ${ }^{49,50)}$ The dielectric relative loss factor (rlf) is also calculated from $\left(\tan \delta / \varepsilon_{\mathrm{r}}\right)$ to measure the purity of the sample. Low rlf values correspond to high purity.

The variation in $\mathrm{AC}$ conductivity $\left(\sigma_{\mathrm{ac}}\right)$ with frequency at (RT) is illustrated in Fig. 8(a-b) It is obvious from the $\log \sigma$ versus $\log \omega$ plots that the total AC conductivity is a sum of two terms: $\sigma_{\mathrm{ac}}(\omega, T)=\sigma_{\mathrm{dc}}(\mathrm{T})+\sigma_{\mathrm{ac}}(\omega)$, where the first term is temperature dependent and independent of frequency. This can be regarded as the DC conductivity, which obeys the

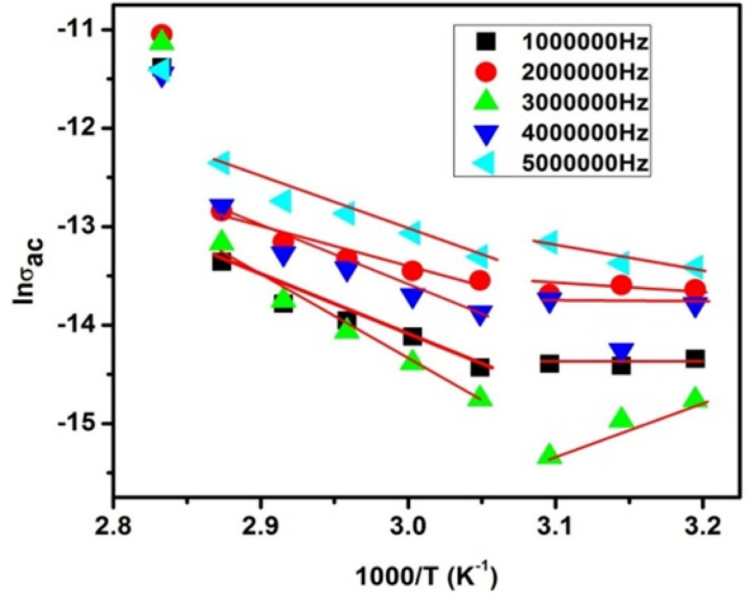

Fig. 9. $\ln \sigma_{\mathrm{ac}}$ versus $10^{3} / \mathrm{T}$ plots of SPION.

Arrhenius relation. The DC conductivity value is calculated to be $2.29 \times 10^{-10}(\mathrm{~S} / \mathrm{cm})$ at RT. Fig. 9 demonstrates the temperature dependence of the $\mathrm{AC}$ conductivity, $\sigma_{\mathrm{ac}}(\omega)$, for the SPIONs. At lower temperatures, conductivity varies with frequency. However, at higher temperatures, the conductivity curves at different frequencies merge, resulting in what is known as intrinsic conductivity. ${ }^{51)}$ The influence of temperature on AC conductivity has been explained by considering the mobility of charge carriers that is responsible for hopping. As temperature increases, the mobility of hopping electrons between $\mathrm{Fe}^{2+} \leftrightarrow \mathrm{Fe}^{3+}$ ions improves, thereby increasing conductivity. This frequency dependent conductivity, $\sigma_{\mathrm{ac}}(\omega)$, which increases with frequency according to Huseynov et al., ${ }^{52)}$ is a common feature to all semiconductor materials.

The AC conductivity was determined using the equation (5):

$$
\sigma_{\mathrm{ac}}=\omega \varepsilon_{\mathrm{r}} \varepsilon_{0} \tan \delta,
$$

where $\omega$ is the angular frequency, $\varepsilon_{\mathrm{r}}$ is the relative dielectric constant, $\varepsilon_{0}$ is the permittivity of free space, and tan $\delta$ is the tangent loss. The AC conductivity versus temperature plots in Fig. 9 show a direct correlation. The AC activation energy, determined from the slope of the linear plot in each region, varies in the ranges $0.325-0.523 \mathrm{eV}$ and 0.482 $0.775 \mathrm{eV}$ for the high $\left(\mathrm{E}_{1}\right)$ and low $\left(\mathrm{E}_{2}\right)$ temperature regions, respectively. The decreasing trend of activation energy is due to increasing conductivity. The linear increase in $\sigma_{a c}$
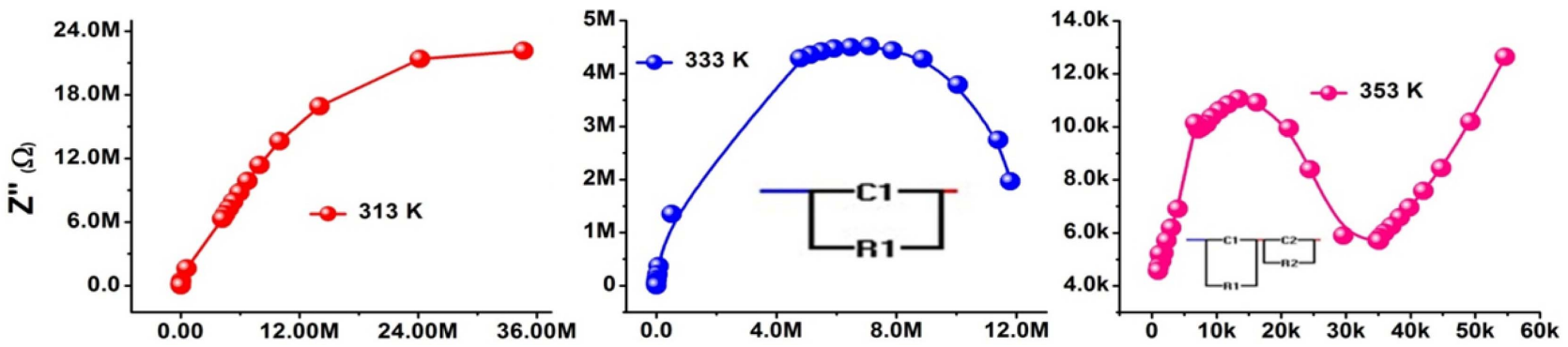

Fig. 10. Z' versus Z" plots (Nyquist plots) of SPIONs. 
reveals the polaron hopping conduction mechanism in the SPIONs. ${ }^{53)}$ At $5 \mathrm{MHz}$, the $\sigma_{\mathrm{ac}}$ value is about $1.08 \times 10^{-3} \mathrm{~S} / \mathrm{cm}$.

The complex impedance measurements ( $\mathrm{Z}^{\prime}$ and $\left.\mathrm{Z}^{\prime \prime}\right)$ at various temperatures between 313 and $353 \mathrm{~K}$ were recorded. Cole-Cole plots were drawn (Fig. 10) at RT. Although semicircles are derived from the data points, the relaxations are of the non-Debye type, since the centers of semicircles lie below the real axis of impedance. However, at higher temperatures, the SPIONs exhibit complete semicircular arcs. The centers of these arcs are above the real axis, and hence confirm that the sample is of high homogeneity and obeys ideal Debye relaxation. ${ }^{54)}$

\section{Conclusions}

SPIONs have been synthesized using a co-precipitation technique, whereby the quantum confinement effect due to particle size leads to a band gap energy of $2 \mathrm{eV}$, which is significantly higher than those found in previous reports $(0.12 \mathrm{eV})$. This greatly improves the UV blocking properties of the $\mathrm{Fe}_{3} \mathrm{O}_{4}$ nanoparticles. The XRD patterns of the samples confirmed their cubic spinel structure, with the space group Fd3m. The FTIR spectrum indicated the presence of absorbed water in the nanoparticulate matrix through peaks that were related to the stretching of the Fe-O bonds. Water might have been trapped inside the matrix even after drying, suggesting that the vibrational structure of the molecule is hydrated. FE-SEM and EDX measurements of the SPIONs revealed that the morphology of the obtained powders is spherical in nature. Trace quantities of $\mathrm{Cl}^{-}$and $\mathrm{S}^{-}$have no impact on the size and shape of the asgrown nanoparticles. The average size of the particles is $12.7 \mathrm{~nm}$, with a narrow particle distribution. HRTEM analysis revealed that only a few $\mathrm{Fe}_{3} \mathrm{O}_{4}$ nanoparticles agglomerated. This condition and the obtained SAED pattern agree with the XRD results. VSM yielded $\mathrm{Ms}, \mathrm{Hc}$, and $\mathrm{M}_{\mathrm{r}}$ values of $29.75 \mathrm{emu} / \mathrm{g}, 8.201 \mathrm{Oe}$, and $0.006 \mathrm{emu} / \mathrm{g}$ at RT, respectively. Complex impedance measurements revealed that the values of $\varepsilon_{\mathrm{r}}$ and $\varepsilon^{\prime \prime}$ of the SPIONs at $5 \mathrm{MHz}$ were 16.3 and 1.05, respectively. The congruence of the resulting Nyquist plot with the Cole-Cole plot implies that the samples exhibit good homogeneity and follow Debye relaxation.

\section{Acknowledgments}

The authors are thankful to Dr. A. Mohan., Department of Physics, School of Advanced Sciences, VIT University, Vellore-632 014, Tamil Nadu, India, for the fruitful discussions.

\section{REFERENCES}

1. A. Bandhu, S. Mukherjee, S. Acharya, S. Modak, S. K. Brahma, D. Das, and P. K. Chakrabarti, "Dynamic Magnetic Behaviour and Mossbauer Effect Measurements of Magnetite Nanoparticles Prepared by a New Technique in the Co-
Precipitation Method," Solid State Commun., 149 [41-42] 1790-94 (2009).

2. O. U. Rahman, S. C. Mohapatra, and S. Ahmad, " $\mathrm{Fe}_{3} \mathrm{O}_{4}$ Inverse Spinal Super Paramagnetic Nanoparticles," Mater. Chem. Phys., 132 [1] 196-202 (2012).

3. Y. Zhan, F. Meng, X. Yang, R. Zhao, and X. Liu, "Solvothermal Synthesis and Characterization of Functionalized Graphene Sheets (FGSs)/Magnetite Hybrids," Mater. Sci. Eng., B, 176 [16] 1333-39 (2011).

4. J. B. Mamani, L. F. Gamarra, and G. E. Brito, "Synthesis and Characterization of $\mathrm{Fe}_{3} \mathrm{O}_{4}$ Nanoparticles with Perspectives in Biomedical Applications," Mater. Res., 17 [3] 542-49 (2014).

5. K. C. Kim, E. K. Kim, J. W. Lee, S. L. Maeng, and Y. S. Kim, "Synthesis and Characterization of Magnetite Nanopowders," Curr. Appl. Phys., 8 [6] 758-60 (2008).

6. M. Li and X. Sui, "Synthesis and Characterization of Magnetite Particles by Co-Precipitation Method," Key Eng. Mater., 512 82-5 (2012).

7. H. Holland and M. Yamaura,"Synthesis of Magnetite Nanoparticles by Microwave irradiation and Characterization"; in Proceedings of the Seventh international Latin Conference on Powder Technology, 2009.

8. T. Sulistyaningsih, S. J. Santosa, D. Siswanta, and B. Rusdiarso, "Synthesis and Characterization of Magnetites Obtained from Mechanically and Sonochemically Assissted Co-precipitation and Reverse Co-precipitation Methods," Int. J. Mater., Mech. Manuf., 5 [1] 16-9 (2017).

9. S. Shaker, S. Zafarian, S. Chakra, K. V. Rao, K. Badii, A. Aftabtalab, and H. Sadabadi, "Fabrication of Super Paramagnetic Nanoparticles by Sol-Gel Method for Water Purification," Adv. Mater. Res., 829 808-12 (2013).

10. H. Ardiyanti, E. Suharyadi, T. Kato, and S. Iwata, "Crystal Structures and Magnetic Properties of Magnetite $\left(\mathrm{Fe}_{3} \mathrm{O}_{4}\right)$ /Polyvinyl Alcohol (PVA) Ribbon," AIP Conf. Proc., 1725 [1] 020007 (2016).

11. T. W. Herrera, A. G. Bustamant Dominguez, E. Baggio Saitovitch, and J. Litterst, "Synthesis and Characterization of Magnetite Nanoparticles Functionalized with Carboxyl and Amino Acids for Biomedical Applications"; pp. 14-5 in Proceeding of the Nano Conference, Brno, Czech Republic, 2015.

12. T. Biswal, B. Barik, and P. K. Sahoo "Synthesis and Characterization of Magnetite-Pectin-Alginate Hybrid Bionanocomposite," J. Mater. Sci. Nanotechnol., 4 [2] 203 (2016).

13. J. Ibarra, J. Melendres, M. Almada, M. G. Burboa, P. Taboada, J. Juárez, and M. A. Valdez, "Synthesis and Characterization of Magnetite/PLGA/Chitosan Nanoparticles," Mater. Res. Express, 2 [9] 095010 (2015).

14. A. Oberle and K. Ludtke-Buzug, "Stability Analysis of Superparamagnetic Iron Oxide Nanoparticles (SPIONs) at $37^{\circ} \mathrm{C}$," Biomed Tech., 58 [1] 4099 (2013).

15. V. K. Garg, E. Kuzmann, V. K. Sharma, Arun Kumar, and A. C. Oliveiral, "Superparamagnetic Iron Oxide Nanoparticles (SPIONs) for Targeted Drug Delivery," AIP Conf. Proc., 1781 [1] 020009 (2016).

16. H. N. Husni, N. Mahmed, and H. L. Ngee, "Synthesis and Characterization of $\mathrm{Fe}_{3} \mathrm{O}_{4}-\mathrm{SiO}_{2}-\mathrm{AgCl}$ Photocatalyst," AIP Conf. Proc., 1756 [1] 090001 (2016). 
17. O. Karaagac and H. Konckar, "A Simple Way to Obtain High Saturation Magnetization for Superparmagnetic Iron Oxide Nanoparticles Synthesized in Air Atmosphere Optimization by Experimental Design,” J. Magn. Magn. Mater., 409 116-23 (2016).

18. K. Petcharoen and A. Sirivat, "Synthesis and Characterization of Magnetite Nanoparticles via the Chemical CoPrecipitation Method," Mater. Sci. Eng., B, 177 [5] 421-27 (2012).

19. H. A. Eivari, A. Rahdar, and H. Arabi, "Preparation of Super Paramagnetic Iron Oxide Nanoparticles and Investigation their Magnetic Properties," Int. J. Sci. Eng. Invest., 1 [3] 70-2 (2012).

20. M. Zarghani and B. Akhlaghinia, "Magnetically Separable $\mathrm{Fe}_{3} \mathrm{O}_{4} @$ chitin as an Eco-Friendly Nanocatalyst with High Efficiency for Green Synthesis of 5-Substituted-1H-Tetrazoles under Solvent-Free Conditions," RSC Adv., 6 [38] 31850-60 (2016).

21. B. K. Sodipo and A. Abdul Aziz, "Blocking Properties of Superparamagnetic Magnetite Nanoparticles and Gold/ Superparamagnetic Magnetite Composite Nanoparticles," Adv. Mater. Res., 1108 15-20 (2015).

22. L. Wang, K. Gan, D. Lu, and J. Zhang, "Hydrophilic $\mathrm{Fe}_{3} \mathrm{O}_{4} @ \mathrm{C}$ for High-Capacity Adsorption of 2,4-Dichlorophenol," Eur. J. Inorg. Chem., 6 890-96 (2016).

23. J. Murbe, A. Rechtenbach, and J. Topfer, "Synthesis and Physical Characterization of Magnetite Nanoparticles for Biomedical Applications," Mater. Chem. Phys., 110 [2-3] 426-33 (2008).

24. S. Gil, E. Castro, and J. F. Mano, "Synthesis and Characterization of Stable Dicarboxylic Pegylated Magnetite Nanoparticles," Mater. Lett., 100 266-70 (2013).

25. M. Morel, F. Martínez, and E. Mosquera, "Synthesis and Characterization of Magnetite Nanoparticles from Mineral Magnetite," J. Magn. Magn. Mater., 343 76-81 (2013).

26. R. Chen, J. Cheng, and Y. Wei, "Preparation and Magnetic Properties of $\mathrm{Fe}_{3} \mathrm{O}_{4}$ Microparticles with Adjustable Size and Morphology," J. Alloys Compd., 520 266-71 (2012).

27. J. Wang, J. Sun, Q. Sun, and Q. Chen, "One-Step Hydrothermal Process to Prepare Highly Crystalline $\mathrm{Fe}_{3} \mathrm{O}_{4}$ Nanoparticles with Improved Magnetic Properties," Mater. Res. Bull., 38 [7] 1113-18 (2003).

28. R. Yuvakkumar and S. I. Hong, "Green Synthesis of Spinel Magnetite Iron Oxide Nanoparticles," Adv. Mater. Res., 1051 39-42 (2014).

29. A. Mohammadi and M. Barikani, "Synthesis and Characterization of Superparamagnetic $\mathrm{Fe}_{3} \mathrm{O}_{4}$ Nanoparticles Coated with Thiodiglycol," Mater. Charact., 90 88-93 (2014).

30. A. Demir, R. Topkaya, and A Baykal, "Green Synthesis of Superparamagnetic $\mathrm{Fe}_{3} \mathrm{O}_{4}$ Nanoparticles with Maltose: its Magnetic Investigation," Polyhedron, 65 282-87 (2013).

31. F. Fajaroh, H. Setyawan, W. Widiyastuti, and S. Winardi, "Synthesis of Magnetite Nanoparticles by Surfactant-free Electrochemical Method in an Aqueous System," Adv. Powder Technol., 23 [3] 328-33 (2011).

32. W. Lu, Y. Shen, A. Xie, and W. Zhang, "Green Synthesis and Characterization of Superparamagnetic $\mathrm{Fe}_{3} \mathrm{O}_{4}$ Nanoparticles,” J. Magn. Magn. Mater., 322 [13] 1828-33 (2010).

33. H. Deligoz, A. Baykal, M. Senel, H. Sozeri, E. Karaoglu, and M. S. Toprak, "Synthesis and Characterization of Poly(1-vinyltriazole)-Grafted Superparamagnetic Iron Oxide Nanoparticles," Synth. Met., 162 [7-8] 590-97 (2012).

34. A. Manohar and C. Krishnamoorthi, "Low Curie-Transition Temperature and Superparamagnetic Nature of $\mathrm{Fe}_{3} \mathrm{O}_{4}$ Nanoparticles Prepared by Colloidal Nanocrystal Synthesis," Mater. Chem. Phys., 192 235-43 (2017).

35. A. M. Yashchenok, D. A. Gorin, M. Badylevich, A. A. Serdobintsev, M. Bedard, Y. G. Fedorenko, G. B. Khomutov, D. O. Grigoriev, and H. Möhwald, "Impact of Magnetite Nanoparticle Incorporation on Optical and Electrical Properties of Nanocomposite LbL Assemblies," Phys. Chem. Chem. Phys., 12 [35] 10469-75 (2010).

36. M. B. Sahana, C. Subakar, G. Setzler, A Dixit, J. S. Thakur, G. Lawes, R. Naik, V. M. Naik, and P. P. Vaishnava, "Bandgap Engineering by Tuning Particle Size and Crystallinity of $\mathrm{SnO}_{2}-\mathrm{Fe}_{2} \mathrm{O}_{3}$ Nanocrystalline Composite Thin Films," Appl. Phys. Lett., 93 [23] 231909 (2008).

37. K. C. Kim, E. K. Kim, J. W. Lee, S. L. Maeng, and Y. S. Kim, "Synthesis and Characterization of Magnetite Nanopowders," Curr. Appl. Phys., 8 [6] 758-60 (2008).

38. D. K. Jha, M. Shameem, A. B. Patel, A. Kostka, P. Schneider, A. Erbe, and P. Deb, "Simple Synthesis of Superparamagnetic Magnetite Nanoparticles as Highly Efficient Contrast Agent," Mater. Lett., 95 186-89 (2013).

39. M. E. Compeán-Jasso, F. Ruiz, J. R. Martínez, and A. Herrera-Gómez, "Magnetic Properties of Magnetite Nanoparticles Synthesized by Forced Hydrolysis," Mater. Lett., 62 [27] 4248-50 (2008).

40. H. Maleki, A. Simchi, M. Imani, and B. F. O. Costa, "SizeControlled Synthesis of Superparamagnetic Iron Oxide Nanoparticles and their Surface Coating by Gold for Biomedical Applications," J. Magn. Magn. Mater., 324 [23] 3997-4005 (2012).

41. I. Martíinez-Mera, M. E. Espinosa-Pesqueira, R. PerezHernandez, and J. Arenas-Alatorre, "Synthesis of Magnetite $\left(\mathrm{Fe}_{3} \mathrm{O}_{4}\right)$ Nanoparticles without Surfactants at Room Temperature," Mater. Lett., 61 [23-24] 4447-51 (2007).

42. O. M. Lemine, K. Omri, B. Zhang, L. E. Mir, M. Sajieddine, A. Alyamani, and M. Bououdina, "Sol-Gel Synthesis of $8 \mathrm{~nm}$ Magnetite $\left(\mathrm{Fe}_{3} \mathrm{O}_{4}\right)$ Nanoparticles and their Magnetic Properties," Superlattices Microstruct., 52 [4] 793-99 (2012).

43. A. Priprem, P. Mahakunakorn, C. Thomas, and I. Thomas, "Cytotoxicity Studies of Superparamagnetic Iron Oxide Nanoparticles in Macrophage and Liver Cells," Curr. Res. Nanotechnol., 1 [2] 78-85 (2010).

44. S. Xuan, Y.-X. J. Wang, J. C. Yu, and K. C.-F. Leung, "Tuning the Grain Size and Particle Size of Superparamagnetic $\mathrm{Fe}_{3} \mathrm{O}_{4}$ Microparticles," Chem. Mater., 21 [21] 5079-87 (2009).

45. V. Kumar, R. P. Singh, S. Kumar, A. Agarwal, and P. Singh, "Particle Size Determination and Magnetic Characterization of $\mathrm{Fe}_{3} \mathrm{O}_{4}$ Nanoparticles Using Superconducting Quantum Interference Device Magnetometry," Sens. Mater., 28 [3] 191-99 (2016).

46. L. Zhuang, W. Zhang, Y. Zhao, H. Shen, H. Lin, and J. Liang, "Preparation and Characterization of $\mathrm{Fe}_{3} \mathrm{O}_{4}$ Particles with Novel Nanosheets Morphology and Magnetochromatic Property by a Modified Solvothermal Method," 
Sci. Rep., 59320 (2015).

47. K. V. P. M. Shafi and A. Gedanken, "Sonochemical Preparation and Size-Dependent Properties of Nanostructured $\mathrm{CoFe}_{2} \mathrm{O}_{4}$ Particles," Chem. Mater., 10 [11] 3445-50 (1998).

48. R. C. Buchanan, Ceramic Materials for Electronics; Third Edition, Marcel Dekker, New York, 2004.

49. M. Srivastava, J. Singh, R. K. Mishra, M. K. Singh, A. K. Ojha, M. Yashpal, and S. Sudhanshu, "Novel Conducting Lithium Ferrite/Chitosan Nanocomposite Synthesis, Characterization, Magnetic and Dielectric Properties," Curr. Appl. Phys., 14 [7] 980-90 (2014).

50. S. Joshi, M. Kumar, S. Chhoker, G. Srivastava, M. Jewariya, and V. N. Singh, "Structural, Magnetic, Dielectric and Optical Properties of Nickel Ferrite Nanoparticles Synthesized by Co-Precipitation Method," J. Mol. Struct.,
1076 55-62 (2014).

51. N. Parasad, G. Prasad, M. Kumar, S. Suryanaryana, T. Bhimasankaram, and G. Kumar, "Effect of HIPing on Conductivity and Impedance Measurements of $\mathrm{DyBi}_{5} \mathrm{Fe}_{2}$. $\mathrm{Ti}_{3} \mathrm{O}_{18}$ Ceramics," Bull. Mater. Sci., 23 [6] 483-89 (2000).

52. E. Huseynov, A. Garibov, and R. Mehdiyeva, "Temperature and Frequency Dependence of Electric Conductivity in Nano-Grained $\mathrm{SiO}_{2}$ Exposed to Neutron Irradiation," Phys. B, 450 77-83 (2014).

53. R. M. Hill and L. A. Dissado, "Debye and Non-Debye Relaxation," J. Phys. C: Solid State Phys., 18 [19] 3829 (1985).

54. B. Behera, P. Nayak, and R. Choudhary, "Impedance Spectroscopy Study of $\mathrm{NaBa}_{2} \mathrm{~V}_{5} \mathrm{O}_{15}$ Ceramic," J. Alloys Compd., 436 [1-2] 226-32 (2007). 